Sergio Zañartu, s.j.

Profesor de la Facultad de Teología

Pontificia Universidad Católica de Chile

\title{
Algunas impresiones sobre la Trinidad en el Vaticano II
}

No pretendo un trabajo acabado (1) ni abarcar todos los aspectos (2). Por eso solo hablo de algunas impresiones. Desde mi perspectiva concreta de años de docencia de los tratados sobre la Trinidad y Cristo, y de investigación de diferentes aspectos de ellos, quisiera ahora aportar una cierta impresión, breve y rápida, aunque trabajada, de algunas de las apreciaciones que surgen en mí al realizar una nueva lectura directa del texto tal como fue promulgado. A mi favor está una distan-

(1) Tampoco pretendo un trabajo genético. A este respecto puede verse N. Silanes, "La Iglesia de la Trinidad”. La Santísima Trinidad en el Vaticano II. Estudio genético-teológico (Koinonia, 14), Salamanca 1981, cap. 3. Muestra el gran cambio que hubo desde lo preparatorio hasta la visión trinitaria del texto definitivo de LG. Anota la influencia del esquema chileno respecto al Espíritu Santo en LG 4. Según E. Vilanova (L'intersessione (1963-1964), p. 486, en G. Alberigo (ed.), Storia del concilio Vaticano II. III: Il concilio adulto. Il secondo periodo e la seconda intersessione settembre 1963-settembre 1964, Bologna 1998, pp. 367-512), el esquema chileno fue fruto del trabajo de J. Ochagavía, E. Vigano y J. Medina, por encargo del Cardenal Silva. Véase A. M. Charrue, Le Saint-Esprit dans Lumen Gentium, pp. 19-29, en Ecclesia a Spiritu Sancto edocta (LG 53). Mélanges thélogiques, Hommage à Mgr Gérard Philips (BEThL, 27), Gembloux 1970, pp. 19-39.

Silanes, en su obra, concluye que la imagen trinitaria de la Iglesia del Vaticano II tiene su fundamento en las misiones divinas. "Esta presentación ha sacado a la Trinidad de su aislamiento para insertarla en un contexto histórico salvífico, en relación con su obra, la Iglesia" (Ib., 199s). Antes había dicho: "El Vaticano II ha sacado al Misterio Trinitario del aislamiento olímpico, al que había sido relegado por la mayoría de los teólogos y pastores de alma, y lo ha acercado al hombre como su 'humus' vital. Ahora podemos contemplar a la Trinidad a través de estas relaciones personales y familiares que ha querido tener con la Iglesia y, en ella, con los hombres" (Ib., p. 105).

(2) Hay aspectos trinitarios a los que no atiendo, por no estar en el centro de mi preocupación actual, p. e. los modos como es dicha nuestra redención por Cristo (sacrificio, redención, salvación, reconciliación, victoria, etc.), o los títulos de Cristo. Anotó sí que nunca usa la tan occidental categoría de satisfacción; tampoco hablará de aplacar la ira de Dios. Algunas veces se referirá a los méritos de Cristo. Sus categorías son más bien bíblicas. En el uso de 'sacrificio' interviene también la importancia que la Eucaristía tiene en los documentos conciliares. No hablará de expiación. Solo citando al Sacramentario Veronense dirá: nostrae reconciliationis processit perfecta placatio (SC 5). Y en LG 8 usará la expresión: repropitiare delicta. Hablará sí de liberación y liberar, y en AG 8 llamará a Cristo "Liberador". 
cia histórica de más de 25 años y las diferentes circunstancias culturales y eclesiales en las que actualmente estoy inmerso. Las diversas referencias a los correspondientes textos del Vaticano II no pretenden ser exhaustivas, y muchas veces son traídas a modo de ejemplo. Otras veces están ausentes porque o se dan por supuestas o no correspondían a mi propósito en ese momento. Presento, pues, a la benevolencia de los lectores esta modesta contribución.

\section{ESCASO USO DE ALGUNOS TÉRMINOS ESPECÍFICOS DE TEOLOGÍA TRINITARIA (3)}

Lo primero que llama la atención en nuestro tema es que, pese al rico contenido trinitario, el vocablo Trinitas solo aparece seis veces y trinum cuatro, todas ellas en LG y UR. Por tanto, el Concilio, que habla muy a menudo de Dios Padre, del Hijo (o Verbo) y del Espíritu en su relación a nosotros (economía), rara vez los engloba bajo esos vocablos. Si tomamos el vocablo persona, veremos que este aparece solo dos veces usado en relación a las personas divinas (dejando a un lado SC 5 (4)), pese a hablar mucho de la persona humana y su dignidad. Estas dos veces son UR 2 (5) y GS 24. Según UR 2, el supremo ejemplar y principio del misterio de la unidad de la Iglesia es la unidad del único Dios Padre e Hijo en el Espíritu Santo (6) en la Trinidad de las Personas (7). Según GS 24, cuando Jesús suplica al Padre que todos sean uno como ellos son uno, insinúa alguna similitud entre la unión de las personas divinas y la unión de los hijos de Dios en la caridad. Y esta similitud manifiesta que el hombre no se puede encontrar plenamente a sí mismo sino por el sincero don de sí mismo (8). La similitud está, pues, entre las dos unidades o uniones. GS lo fundamenta en Jn 17, 21s y saca la conclusión del don de sí mismo, que si lo aplicamos a la unidad divina dice relación a las procesiones, donde, por ejemplo, el Padre da todo al Hijo, menos ser Padre. Estos escasísimos textos en que

(3) Como ayuda para el análisis por término, empleé preferentemente el Index Verborum cum documentis concilii Vaticani Secundi, de X. Ochoa (Institutum Iuridicum Claretianum, Roma (1967).

(4) Cristo es mediador. En efecto su humanidad, en la unidad de la persona del Verbo, fue instrumento de nuestra salvación. Se habla, entonces, de la persona del Verbo, pero en cuanto mediador, porque tiene como instrumento unido a él su humanidad. Dicho de otra forma, la unidad de Cristo le viene de la persona del Verbo (la dualidad es de las naturalezas). Esta fórmula agradaría a los oídos alejandrinos. Se alude, además, indirectamente a la persona de Cristo, cuando se dice que el obispo o el presbítero actúa in persona Christi (SC 33; LG 10; 21; 28; 37; AG 39; PO 2; 12). Finalmente, tenemos dos textos referidos a la persona de Cristo con cierta distinción respecto a su obra: "Ante todo el reino se manifiesta en la misma persona de Cristo, Hijo de Dios e Hijo del hombre" (LG 5); María se consagró totalmente a la persona y obra de su Hijo (LG 56). Por tanto, cuando se habla de persona en estos casos, se refiere al encarnado y SC 5 es en relación a la encarnación redentora y no a la persona del Verbo en referencia a las otras personas trinitarias.

(5) Igualmente aquí se aludiría, y solo aquí, a la mutua presencia entre el Padre y el Hijo en la cita de Jn 17, 21, pero esto es en la perspectiva económica de la unidad de los cristianos.

(6) Cf. UR 7. Véase en LG 27 la exhortación a la adhesión de los fieles al obispo, como la Iglesia a Jesucristo, como este al Padre, para que todo sea concorde en la unidad (cf. Ignacio, Ef 5, 1).

(7) El único Dios parece referirse a Dios uno, que es Padre e Hijo. En ese sentido, la 'dinámica' en el decir no partiría aquí del Padre sino del Dios uno. Esto reflejaría más bien una teología occidental. La unidad es en el Espíritu Santo. Y cita a Lc 17, 33 . 
se emplea persona para la Trinidad, de hecho van a ser muy continuados en el postconcilio por aquella teología trinitaria que destaca la comunidad trinitaria como prototipo de la comunidad eclesial y humana. Si pasamos ahora a otro componente básico de la explicación trinitaria, la relación, encontramos que este vocablo no es mencionado en referencia a la Trinidad. Finalmente, no me pareció encontrar explícitamente ninguna alusión a la explicación sicológica agustiniana tomista.

Volviendo al escaso uso del vocablo Trinitas, este aparece por primera vez cerrando el capítulo quinto de LG (9) sobre la vocación universal a la santidad en la Iglesia: "para la mayor gloria de la una e indivisa Trinidad, que en Cristo y por Cristo es la fuente y el origen de toda santidad". Y en el número 51 se hablará de la alabanza de la santísima Trinidad en la que mutuamente se comunican los fieles de la tierra con los del cielo (10). Finalmente termina esta constitución (LG 69) con la congregación de todos en un pueblo para gloria de la santísima e individua Trinidad. El texto de UR 14 (11) alude a la Trinidad (y Encarnación) como un dogma fundamental de la fe cristiana, y UR 15 afirma que, teniendo el acceso al Padre por el Hijo en el Espíritu, se consigue la comunión con la santísima Trinidad, hechos consortes de la naturaleza divina $(2 \mathrm{P} 1,4)$. En este texto, la Trinitas, igual que en los textos anteriores de alabanza y glorificación, está inserta en la economía de Dios. La Trinidad, en UR 15, aparece de hecho en cierto contrapunto a la naturaleza divina de la que participamos. Esta participación de la naturaleza divina también la encontramos en LG 40; DV 2 (12) y AG 3, y nunca más se habla de natura en referencia a la divina (13). Si nos fijamos en el vocablo trinus, vemos que se menciona el Dios trino y uno (o uno y trino), a quien se contempla claramente, tal como es, en el cielo (14) (LG 49); a quien se magnifica en un mismo canto de alabanza (LG 50); en quien creen todos los cristianos UR 12). En el movimiento ecuménico participan los que invocan al Dios trino (UR 1)

Por tanto, el uso de los términos vistos, que es escaso, nos lleva a una clara conclusión. No trata el Concilio Vaticano II de la Trinidad en sí, de la inmanente, sino que siempre habla en una perspectiva económica (15). Los textos que más entran, por

(9) LG 47.

(10) Esto va justamente después de haber dicho que el culto latréutico es al Dios Padre por Cristo en el Espíritu, lo que muestra la táxis de la glorificación económica.

(11) Dejamos a un lado el número 2, ya visto, sobre la unidad de los tres en la Trinidad de personas.

(12) Sigue al acceso al Padre, pero sin poner la comunión con la Trinidad.

(13) Tampoco utiliza substantia y essentia.

(14) Cf. DH 1305.

(15) N. Silanes ("La Iglesia de la Trinidad", 9s) introduce así: "El Concilio ha dado por supuesta la ontología trinitaria. El carácter pastoral del Concilio, sin embargo, y el haber constituido a la Iglesia en tema central de su reflexión, hizo aflorar a la Trinidad como 'clave de bóvedad' de todo el misterio cristiano. Una comprensión de la Iglesia en su dimensión de misterio y sacramento, tal como nos la ha ofrecido el Vaticano II, ha puesto de relieve a la Trinidad como razón primera y última de su ser y de su misión. La Iglesia, como misterio, en efecto, es la res proyectada por el Padre, realizada por el Hijo en toda su obra salvífica y alentada por el Espíritu. La Iglesia es, en definitiva, una misteriosa extensión en el tiempo del Misterio mismo del ser divino, que es una comunión de vida compartida. La Iglesia participa en Cristo la filiación divina y está ordenada a la comunión definitiva con las tres personas 'en casa del Padre'. Es así como nos presenta la revelación a la Trinidad y como la entendieron, vivieron y predicaron los Padres: la Trinidad en relación con su economía". Y en la conclusión (Ib., 445s) añadirá: "La necesidad 
así decirlo, en la Trinidad en sí, son los dos textos referidos a la unión o unidad de las Personas divinas, que es aludida justamente como prototipo de la unión de la Iglesia y de los hombres, por tanto, también desde una perspectiva económica.

En AG 2 llama a Dios Padre "principio sin principio del que es engendrado el Hijo y de quien procede el Espíritu Santo por el Hijo". Esto que parece tocar tan directamente a la Trinidad en sí, está, sin embargo, enmarcado en las misiones del Hijo y del Espíritu, de las que toma su origen la Iglesia misionera, según el plan del Padre. Y este plan fluye del fontanal amor del Padre, que crea libremente y llama graciosamente a que comuniquemos con él en la vida y en la gloria, difundiendo liberalmente su bondad divina. Por tanto, son procesiones enmarcadas en la economía. Al decir que el Espíritu procede por el Hijo, usa la fórmula querida por los orientales (nunca usa el Filioque), pero esto también se explica porque ella es una fórmula más dinámica para la misión (16).

Pese a no tratar de la Trinidad en sí, es un concilio eminentemente trinitario (17) en su visión pastoral, como se manifiesta por la enormidad de textos en que aparecen actuando el Padre, el Hijo y el Espíritu (18), o algunos de los tres, en relación a nuestra salvación. Actúan, por tanto, en la economía, en la historia de salvación (19). Para expresar esto, el Concilio usa principalmente el lenguaje neo-

de exconjurar el subordinacionismo llevó al Magisterio y a la teología a acentuar la igualdad esencial de las tres Personas y la unicidad de operación ad extra con el consiguiente peligro de diluir la peculiaridad personal respectiva en el actuar del Dios Trino. El Concilio, en consonancia total con la Escritura, ha presentado a cada una de las Personas, actuando como tal Persona. El Padre en su condición de Padre; el Hijo como tal Hijo y el Espíritu Santo en su propiedad peculiar de Espíritu. Cada una de las personas divinas se ha manifestado en la historia de la salvación actuando la misma obra salvífica, pero según su condición 'nocional' o 'personal'". En Vaticano II, p. 1428s (en Diccionario teológico. El Dios Cristiano, Salamanca 1992, pp. 14251433) dirá este mismo autor: "Esta óptica (SS. Trinidad en el marco de la economía salvífica) es una constante en todos los documentos conciliares, salvo raras excepciones, en las que aparecen expresiones más esencialistas o estáticas. Con ello el Concilio ha conectado con la más pura tradición bíblica y patrística, sobre todo oriental, que ha contemplado siempre el actuar trinitario 'ad extra' según el orden de sus procesiones".

(16) El texto anterior decía que el Padre es principio sin principio, del que proceden la persona del Hijo y la persona del Espíritu Santo (Acta Synodalia, IV, 6, p. 208). Se lo enmendó para aclarar la diversidad de las procesiones, respondiendo a diversos modos de 10 Padres (Acta Synodalia, IV, 7, p. 14).

(17) Antes de terminar el Concilio exclamaba M. Philippon (La Santísima Trinidad y la Iglesia, p. 341, en G. Baraúna, La Iglesia del Vaticano II. Estudios en torno a la Constitución conciliar sobre la Iglesia, I, Barcelona 1968, $3^{\text {a }}$ ed., pp. 341-363): “Todas las enseñanzas del concilio sobre el misterio de la Iglesia están marcadas con el 'sello de la Trinidad'. La naturaleza íntima de la Iglesia encuentra en el misterio trinitario sus orígenes eternos, su forma ejemplar y su finalidad".

(18) "No menos de cincuenta veces son las ocasiones en las que aparecen conjuntamente las tres personas en los diversos documentos conciliares en función de la salvación del hombre" (Silanes, Vaticano II, 1427). Omite los párrafos más amplios.

(19) Así el Vaticano II nos presenta una Trinidad dinámica y no una Trinidad en sí. El vocablo historia aparece 64 veces, de las que 33 corresponden a GS, donde muchos textos se refieren a la historia humana. Pero el misterio de Cristo afecta toda la historia humana (OT 14). Con la misión de Cristo, Dios entró de modo nuevo y definitivo en la historia de los hombres (AG 3; cf. GS 38). En Cristo se encuentra la clave, el centro y el fin de toda la historia humana (GS 10). Su consumación será cuando todo esté instaurado en Cristo (cf. GS 45). Y así como hay un único Dios Salvador, que es el Creador, así también un único Señor lo es de la historia humana y de la historia de salvación (GS 41). La compenetración de la ciudad terrestre y celeste es el misterio de la historia humana (GS 40). Así igualmente, aunque hay que distinguir el progreso terreno del crecimiento del reino de Cristo, sin embargo aquel interesa en gran manera al reino de Dios, en cuanto sirva para mejor ordenar la 
testamentario, en el cual brilla, por así llamarla, la 'monarquía' del Padre, de quien todo viene y a quien todo vuelve. El gran servicio del Vaticano II, en nuestro tema, es haber presentado el misterio cristiano, especialmente la Iglesia con su liturgia, etc., la revelación y el mundo del hombre, trinitariamente. Esto de manera tal, que no se pueda concebir la teología sino empapada de Trinidad (20).

\section{¿TEOLOGÍA DEL DIOS UNO?}

Aunque la acción trinitaria es preponderante, una pregunta digna de investigar sería hasta dónde se habla a veces del Dios uno, que es trino, o de Dios sin explicitar la Trinidad; hasta dónde el Dios uno puede reemplazar o desplazar al Padre (21). Creería que fundamental o significativamente no. Porque cuando se habla de Dios, sin llamarlo explícitamente Padre, fácilmente aparece, en ese texto o en su contexto, o enviando al Hijo u obrando por este en el Espíritu, etc. Igualmente la vuelta es en el Espíritu por el Hijo hacia él. Esto sería lo normal y muy repetido. ¿Pero hay algunos textos que, reflejando un poco los tratados De Deo uno, insinúen el Dios que no sea necesariamente y en cierto sentido solo el Padre? (22). Esto sería más diáfano si se tratara de la Trinidad en sí y entonces se hablara de la esencia divina común a los tres y se estudiaran sus atributos esenciales. Pero eso, como acabamos de ver, está ausente del Vaticano II (23). Cuando habla de la Providencia de Dios, ¿a qué persona se refiere o solo al Dios uno? Con todo, la Providencia puede estar explícitamente relacionada al plan de Dios, que es el del Padre (24). Más acuciante puede ser la pregunta cuando se habla de vivir sin Dios o para él, del conocimiento de Dios, de Dios como sentido del hombre, etc. Es evidente que 'Dios' no se dice solo del Padre, en textos p. e. de alabanza a Dios, Padre e Hijo y Espíritu Santo (25) o cuando se habla del Dios trino. Creo que no siempre se podrá ver claro en este asunto (26).

sociedad humana (GS 39). Más directamente sobre la historia de salvación, dentro del uso del término historia, hablaría el Vaticano II unas 23 veces. Si en SC 16 alude al misterio de Cristo y a la historia de salvación, en SC 35 los identifica (véase PO 22). El uso, en general, del vocablo historia es, pues, un indicio de la perspectiva histórica del Concilio.

(20) En este sentido la Trinidad no es un tratado aparte.

(21) Según Silanes ("La Iglesia de la Trinidad”, p. 231 n 31), 121 veces se utiliza el término 'Padre' referido a la primera persona de la Trinidad. Según C. Molari (Dio, col. 1002, en S. Garofalo (ed.), Dizionario del Concilio Ecumenico Vaticano Secondo, Roma 1969, col. 1001-1007), “... en numerosos otros textos se siente el reflejo de una terminología sucesiva que usa el nombre 'Padre' para indicar la primera persona y utiliza el nombre 'Dios' para designar los aspectos comunes a la divinidad".

(22) Por supuesto que el Hijo, alguna vez, también es llamado directamente Dios (LG 8; 48; UR 20; AG 3) o se habla de la Madre de Dios.

(23) En UR 2 parecería referirse al Dios uno, que es Padre e Hijo en el Espíritu.

(24) Así en PC 13 se habla de la Providencia del Padre. Cf. DV 3.

(25) P. e. UR 20; PO 5.

(26) Según Silanes ("La Iglesia de la Trinidad", 229-231), "hasta 867 veces aparece en los documentos conciliares el término 'Dios' por el Padre. Cuando habla del A. T. incluso, el Concilio emplea el término 'Dios' indicando al Padre. En determinadas ocasiones, principalmente cuando el Concilio se dirige a los no cristianos, ha empleado el término 'Dios', por el 'Ser absoluto', autor y árbitro supremo de todo lo existente, que puede ser descubierto desde el hombre... Tampoco el nombre 'Dios' está por el Padre en algunas ocasiones en las que el término se refiere a toda la Trinidad... El 
Yo solo quiero detenerme, a este respecto, en unos textos que me llamaron la atención sobre Dios creador y redentor. El tema del Creador, que ya está comprendido en el designio salvador (restaurador) del Dios cristiano, y que, por otra parte, es tema común entre las religiones, aparece con fuerza a propósito de las realidades temporales. Así de las 35 veces en que encontramos Creator, 23 están en GS. Y si se habla de creación desde la fe en Cristo, fácilmente se aludirá también a la redención. Así se llega a las siguientes expresiones sobre el Dios creador y redentor (27). Según LG 31, a los laicos compete de modo especial iluminar y ordenar las cosas temporales de tal modo, que se hagan y crezcan según Cristo y sean para alabanza del Creador y Redentor. Y en GS 50 afirma que el amor conyugal y la vida de familia tienden a que cooperen los esposos con el amor del Dios Creador y Salvador, que por medio de ellos dilata y enriquece Su familia. Según GS 41, el mismo Dios que es Salvador, es también el Creador; igualmente el mismo Señor es no solo de la historia humana sino también de la historia de salvación, lo que no quita la justa autonomía de la creatura, sino más bien la restituye a su dignidad y la afirma (28). Podemos nosotros pensar, en referencia a estos textos, que el Creador es el Dios Padre (29), como lo decimos en el Credo, pero crea por su Verbo (30). Por otra parte, también el Padre es Salvador, mediante su Hijo y el Espíritu. Sea lo que sea de estas expresiones, como de otras posibles alusiones al Dios uno, el conjunto del Vaticano II nos mostraría normalmente al Padre (muchísimas veces con el nombre de Dios y unas 147 veces con el de Padre), al Hijo y al Espíritu Santo, actuando en nuestra salvación. Decididamente habla trinitariamente de Dios, aunque no excluya otras expresiones (31).

Concilio abunda en la expresión 'Madre de Dios', en la que el término 'Dios' está por el Hijo... La expresión 'Hijo de Dios' referida a Cristo e 'hijos de Dios', dicha de los hombres, que utiliza frecuentemente el Concilio, es sinónima de Hijo e hijos del Padre respectivamente". Sobre el referirse a toda la Trinidad, cf. p. e. LG 49; 50; PO 5; AA 16; UR 1; 2; 20; GS 19.

(27) El texto de AA 16 puede ser leído trinitariamente.

(28) Según AA 5, los laicos ejercen su apostolado tanto en el orden espiritual como temporal, los cuales órdenes, aunque se distingan, de tal manera están conectados en el único plan de Dios, que el mismo Dios pretende reasumir en Cristo todo el mundo hacia la nueva creatura. Cf. p. e.: AA 7; GS 36; 39; 61. Véase CD 12; GE 2. GS 59 habla de un doble orden del conocimiento, citando al Vaticano I (cf. LG 33). Véase DH 2. En AG 22 se habla de lo que sirve para confesar la gloria del creador e ilustrar la gracia del Salvador. Según LG 2, el Padre creó y decretó elevar a la participación de la vida divina.

(29) P. e. LG 17.

(30) P. e.: DV 3 (crea y conserva y se manifiesta desde el comienzo...) (cf. LG 7); AG 3 (a su Hijo, por quien hizo los siglos, lo constituyó heredero); GS 38 y 45 (por quien todo fue hecho, él mismo se hizo hombre para asumir, salvar, recapitular).

(31) No reflexiona explícitamente sobre la trascendencia de Dios respecto al hombre, tema que fácilmente se podría desarrollar en relación al De Deo uno. Quizás esto se deba, en parte, a una visión más unitaria y positiva de la relación entre el mundo y Dios. En este sentido, transcendere solo es usado para los actos religiosos que se ordenan a Dios (DH 3; cf. LG 9; PO 15). Tampoco usa, respecto al conocimiento de Dios, analogia. Pero repite lo del Vaticano I: los bienes divinos, para participar de los cuales Dios se nos comunica en su revelación, superan del todo la inteligencia humana (DV 6; cf. LG 6; AG 13; GS 39). 14 veces utiliza supernaturalis. La belleza divina es infinita (SC 122), igual que el poder del Espíritu (LG 44). Igualmente, usa a menudo la palabra mysterium. En NA 1 se refiere al último e inefable misterio que abraza nuestra existencia, "del cual tomamos origen y al que tendemos". Según LG 3 (cf. GS 22), Cristo nos reveló el misterio del Padre. El misterio de la Encarnación es llamado 'sumo' (LG 65). Cf. UR 2. La trascendencia de Dios se nos va a manifestar también en la libertad y gratuidad de su actuar, etc. 


\section{LA UNIDAD TRINITARIA EN LA ECONOMÍA}

Aunque explícitamente aluda muy poco, como lo hemos estado viendo (32), a la unidad de las personas divinas en la Trinidad, esta es evidente en todo el actuar económico (33), siendo la unidad, por lo demás, el designio de Dios (34). Esta economía unitaria, de la que aquí mencionaremos solo algunas cristalizaciones (35), se manifiesta con toda su fuerza en el comienzo de LG. El Padre, en un designio libérrimo y bondadoso, crea el universo y decreta elevar al hombre a la participación de la vida divina (LG 2). El Padre envió a su Hijo para instaurar todo en él (LG 3). Y en Pentecostés es enviado el Espíritu Santo para santificar, lo que da nacimiento a la Iglesia como pueblo (plebs) reunido en (de) la unidad del Padre y del Hijo y del Espíritu Santo, según la fórmula de Cipriano (LG 4) (36). Según AG 2, este propósito fluye del amor fontanal o caridad de Dios Padre, que siendo principio sin principio, del que es engendrado el Hijo y el Espíritu procede por el Hijo, por su excesiva y misericordiosa benignidad, creando libremente y llamándonos además graciosamente a participar con él en la vida y en la gloria, difundió y no cesa de difundir liberalmente su bondad divina, de manera que el que es Creador de todo, finalmente sea todo en todos (1Co 15, 28), procurando su gloria y, a la vez, nuestra felicidad (37). Otra

(32) LG 47; 49; 50; 69; UR 1; 2; 12; 15; GS 24. Cf. LG 39; 40; AG 3; DV 2.

(33) Silanes ("La Iglesia de la Trinidad", 440s), después de un catálogo de efectos salvíficos que se aplican a más de uno de los tres, lo que muestra que la obra es común, concluye así: "El Concilio ha puesto de manifiesto el mismo modo de hablar de la Escritura, en el que se aplican idénticos efectos salvíficos a las distintas Personas divinas. Con ello se reconoce la unidad de operación de las tres Personas, si bien esta unidad de operación fluye de cada una de ellas según su orden personal. Del Padre, en cuanto principio fontal (a quo) de la divinidad y de todas las obras ad extra; del Hijo como Mediador, por quien (per quem) el Padre crea y recrea todo en él, y del Espíritu Santo, en quien (in quo) el Padre por el Hijo completa su obra... El Concilio, dentro de su línea pastoral y en consonancia con la doctrina bíblica y patrística, ha puesto en primera línea a las Personas y su actuación respectiva, según su orden. Pero, al mismo tiempo, sin entrar en cuestiones dogmáticas, resueltas por otra parte, ha presentado la unidad de operación, dentro de la economía divina, sobre todo, en las fórmulas triádicas y al asignar idénticos efectos salvíficos a las tres Personas". La Comisión Doctrinal del Concilio se negó a una distinción más nítida entre lo propio y lo apropiado de las personas; quiso permanecer al nivel del lenguaje de la Escritura, de los símbolos de fe y de los concilios. "No parece que haya que entrar en explicaciones teológicas ulteriores”. Pretendió, pues, presentar la Trinidad según la función (munus) respectiva de las tres personas. Cf. Ef 1. (Cf. Acta Synodalia III, I, p. 171).

(34) P. e.: LG 13; UR 2; AA 7; AG 2; 7; GS 24; 32; 78; 92. Entre otras cosas, podemos también tener en cuenta todo lo que se dice respecto a la unidad a propósito de las misiones del Hijo, del Espíritu, de la Iglesia; igualmente el instaurar todo en Cristo y que al final Dios va a ser todo en todos.

(35) Respecto a las fórmulas triádicas, cf. la lista de Silanes, “La Iglesia de la Trinidad”, p. 101 n. 73.

(36) AG 2: La Iglesia misionera se origina en la misión del Hijo y en la misión del Espíritu Santo, según el propósito de Dios Padre.

(37) "El misterio de la Iglesia es la realización en la historia del designio del Padre eterno, consumado por su Hijo e interiorizado por su Espíritu: así se pueden resumir los dos textos fundamentales del Vaticano II sobre la eclesiología trinitaria (LG 2-4; AG 2-4)" (B. de Margerie, La trinité chrétienne dans l'histoire (Théologie Historique, 31), Paris 1975, p. 304). "La tela de fondo de esta eclesiología trinitaria no es otra que el prólogo de la Epístola a los Efesios" (Ib., 305; cf. Philippon, op. cit., 347-349). Margerie dirá después: “¿El concilio Vaticano II nos ha querido mostrar en la Iglesia -que las vuelve en cierta manera visibles en la historia- la prolongación de las procesiones divinas del Verbo y del Espíritu y, si se osa decir, el despliegue histórico del 
muestra es que en el Vaticano II el verbo mitto (missus), que los relaciona entre ellos, es empleado unas 44 veces en referencia a la misión del Espíritu y sobre todo del Hijo por el Padre (38).

El bautismo es en el nombre de los tres (39). La Iglesia, entre otras connotaciones trinitarias, es llamada pueblo de Dios, cuerpo de Cristo y templo del Espíritu Santo (40). La Iglesia procede del amor del Padre eterno, es fundada en el tiempo por Cristo Redentor y reunida en el Espíritu Santo (41). Y los cristianos, al estrechar su comunión con el Padre, el Verbo y el Espíritu, pueden más íntima y fácilmente aumentar la fraternidad mutua (42). Cristo con el Padre y el Espíritu es celebrado como el solo santo (43). El culto latréutico se tributa a Dios el Padre por Cristo en el Espíritu (44). Cristo en su misión fue enviado por el Padre y ungido por el Espíritu (45). En su rostro resplandece la claridad de Dios que brilla para todos por el Espíritu $(2 \mathrm{Co} 4,6)(46)$. Y el acceso al Padre es por Cristo en el Espíritu (Ef 2, 18) (47). Todo está dirigido a la gloria del Padre (48). "A aquel que es poderoso para hacer todo más sobreabundantemente de lo que pedimos o entendemos... a él sea la gloria en la Iglesia y en Cristo Jesús por todas las generaciones de los siglos. Amén (Ef 3, 20s)" (GS 93) (49). Los cristianos, reunidos en Cristo, son dirigidos por el Espíritu Santo al reino del Padre (50). Todas las cosas son de ellos, ellos de Cristo y Cristo de Dios

misterio trinitario?... Parece que el decreto Ad Gentes sobre las misiones ha querido completar, en el plano trinitario, el fresco de Lumen Gentium" Ib., 307). "La Iglesia solo es sacramento de salvación, porque ella es el sacramento de la Trinidad, el signo visible que lleva en ella la invisible e indivisible Trinidad para darla al mundo. Recibiendo su unidad de la unidad del Padre, del Hijo y del Espíritu, la Iglesia es, por así decirlo, eternamente engendrada con el Hijo y espirada con el Espíritu, que le son enviados y que en ella proceden del Padre... La Santísima Trinidad, a los ojos de este concilio, es la fuente, el modelo y el término o el fin de la única Iglesia universal, su templo y su sacramento" (Ib., 307s).

(38) Así el Padre lo santificó y envió al mundo (Jn 10, 36) (LG 28; AG 3; PO 2; 12). El vocablo missio es empleado unas 15 veces en referencia a la misión del Hijo y del Espíritu.

(39) LG 17; DH 1; AG 5. Véase GS 92.

(40) LG 17; AG 7; PO 1. Cf. LG 9. María es verdadera Madre de Dios Hijo, y por tanto, hija predilecta del Padre y también sagrario del Espíritu Santo (LG 53). Respecto a la relación entre el Espíritu y María, puede verse Chantraine, L'enseignement de Vatican II concernant l' Esprit Saint, pp. 1003s, en Credo in Spiritum Sanctum. Atti del Congresso Teologico Internazionale di Pneumatologia. II, Vaticano 1983, pp. 993-1010.

(41) GS 40. Véase GS 1.

(42) UR 7. La unidad de los que confiesan al Padre y al Hijo y al Espíritu Santo es impulsada por el Espíritu (cf. GS 92). Cf. UR 24.

(43) LG 39. Cf. LG 47.

(44) LG 51. Cf. PO 5. El culto de adoración es al Verbo encarnado, igual que al Padre y al Espíritu (LG 66). En la ciudad celeste se adorará a Dios y al Cordero (LG 51). El culto es dado al Padre por Cristo sacerdote, junto con nosotros su cuerpo (SC 7; 83; 84; cf. LG 17).

(45) Cf. AG 3.

(46) AG 42.

(47) LG 4; 28; UR 15; DV 2; PO 6; 12. Cf. OT 8. Véase PO 2; 18. Cristo resucitó destruyendo la muerte con su muerte, y nos regaló la vida, para que hijos en el Hijo, clamemos en el Espíritu: Padre (GS 22). Silanes ("La Iglesia de la Trinidad”, pp. 342-346) atribuye bastante importancia a este texto.

(48) Se hablaría de gloria de Dios o gloria del Padre en unos 32 textos. Se usa también en este sentido glorificatio y glorificare 18 veces, y laus y laudare unas 21 veces. Véase LG 51. En UR 20 es la gloria de Dios Padre e Hijo y Espíritu Santo (cf. LG 47; 69; véase LG 51).

(49) Cf. PO 22

(50) GS 1. 
(1Co 3, 22s) (51). La comunidad cristiana pasa incesantemente con Cristo al Padre mediante el sacrificio eucarístico (52). Al final todo será sometido en Cristo al Padre y así Dios será todo en todos $(1$ Co 15,28$)(53)$. Seremos en verdad a imagen y semejanza de Dios (designio del Creador), cuando todos, regenerados en Cristo por el Espíritu, unánimente contemplando la gloria de Dios, podamos decir: Padre nuestro (54). En conclusión, este 'movimiento' económico desde el Padre y hacia él, en el que intervienen las misiones del Hijo y del Espíritu, muestra a las claras la unidad de Dios. No se trata de tres actores diferentes que se asocian para una obra común, lo que daría pie a una visión de tinte triteísta (55). Y mucho más lejos de este cuadro trinitario estaría el autodesenvolvimiento de un sujeto absoluto.

\section{EL PADRE Y EL VERBO}

Como hemos visto, el Padre Creador (por amor (56)) es el de la iniciativa: designio, propósito, voluntad (de Dios), predestinación (57). Él envía, llama. Envía al Hijo, lo constituye heredero de todas las cosas (58). Es Padre del Hijo y de todos los hijos de Dios (59). También es providente (60) y da sus dones (61). Según DV 21 (62), el Padre celestial, mediante la Escritura, conversa con los hombres. Nosotros diríamos que Dios actúa por el Hijo en el Espíritu (63). Pero si el Padre es el origen y término de todo (64), Cristo es el centro (65). Poco se habla

(51) LG 36; GS 37. Los fieles deben adherir al obispo como la Iglesia a Jesucristo, y como este al Padre, para que todo se armonice por la unidad y abunde para la gloria de Dios (cf. Ignacio, Ef 5, $1 ; 2 \mathrm{Co} 4,15)$ (LG 27).

(52) AG 15

(53) AG 21. Cf. LG 36. Véase SC 48. Cristo entregará el reino al Dios y Padre (PO 2; GS 39). Así el que es Creador de todo llega finalmente a ser todo en todos (AG 2; cf. GS 92).

(54) AG 7. Los documentos del Vaticano II son aprobados en el Espíritu Santo y promulgados para gloria de Dios, actuando el Papa con la potestad apostólica recibida de Cristo.

(55) Temas de algunos autores postconciliares, como ver en la pasión un drama entre el Padre y el Hijo, no aparecen en el Vaticano II (tampoco el simple dolor del Padre). Porque simplemente el Padre obra por el Hijo y este obedece la voluntad de Dios.

(56) Recordemos que Dios es caridad y difunde su caridad en nuestros corazones por su Espíritu (LG 42). Cf. UR 2; 24; PC 15; AA 4; AG 2; GS 38. Veáse también p. e.: PC 6; 14; NA 4; DV 2; 14 ; AA 30; AG 10; 12; 13; PO 18; 22; GS 19; 32; 40; 45; 50; 93. Envió el Espíritu Santo para que los moviera internamente a amar a Dios y a amarse entre ellos, como Cristo los amó (LG 40).

(57) LG $2 ; 3 ; 56 ; 61$.

(58) LG 13; AG 3. Lo resucita y exalta a su derecha, constituyéndolo juez de vivos y muertos (GS 45).

(59) Estos claman 'Abba' (SC 6; PO 18; GS 22; cf. AG 7). Según Silanes ("La Iglesia de la Trinidad”, 251), "aparece claro la intención del Concilio de presentar la filiación adoptiva del hombre como la razón última del designio del Padre, de la misión de Cristo y del cometido de la Iglesia".

(60) También se habla de una 'pedagogía' de Dios (DV 15). Cf. AG 13. Véase p. e. UR 1; 24; AG 9.

(61) Así, por ejemplo, el celibato por el reino es un gran don que el Padre concede a algunos (LG 42; cf. OT 10; PO 16). También, entre otras cosas, Dios es el que nos prepara la nueva habitación, la tierra nueva (GS 39).

(62) Cf. DV 2;8;25.

(63) P. e. LG 13; DH 15; AG 2, etc.

(64) P. e. GS 92. Para una visión más completa de la acción del Padre, puede verse Silanes, "La Iglesia de la Trinidad”, 231-243; J. Debesa Castro, El concepto de Dios Padre en los documentos del concilio Vaticano II. Tesis para Licencia en Teología, Santiago de Chile 1988, manuscrito.

(65) Así, por ejemplo, se identifica la historia de salvación con el misterio de Cristo (SC 35; cf. PO 22). Así también en LG 3, se afirma que procedemos de Cristo, por él vivimos y a él tendemos 
del Verbo antes de la Encarnación, fuera de decir, como ya hemos visto, que Dios creó todo por su Verbo. Antes de que se hiciera carne para salvar y recapitular (66), el Verbo ya estaba en el mundo, como "luz que ilumina a todo hombre" (1 Jn 1, 9) (67). Y según citas de Ireneo (68), el Verbo, por el que todo fue hecho, siempre ha asistido al género humano y revela a todos el Padre, según el querer de éste. AG 11 nos habla de las latentes semillas del Verbo que hay que descubrir con alegría y reverencia (69).

\section{LA ENCARNACIÓN}

Volvamos ahora al misterio sumo (70) de la Encarnación. Según AG 3, "Cristo fue enviado al mundo como verdadero mediador entre Dios y los hombres. Siendo Dios, 'habita en él corporalmente la plenitud de la divinidad' (Col 2, 9); según la naturaleza humana, nuevo Adán, es constituido cabeza de la humanidad renovada, 'lleno de gracia y de verdad' $(J n$ 1, 14) (71). Y así, por los caminos de la verdadera

(cf. Discurso inaugural de Pablo VI, 29 de septiembre de 1963). Como ya vimos, él es la clave, centro y fin de toda la historia humana. Véase LG 2.

J. Alfaro (Cristología y antropología. Temas teológicos actuales, Madrid 1973, p. 110s) se expresa así respecto a la cristología del Concilio: "El Concilio Vaticano II no ha pretendido dar una visión completa del misterio de Cristo; pero ha puesto de relieve los aspectos fundamentales de este mismo, sobre alguno de los cuales hasta ahora poco o nada había dicho el magisterio de la Iglesia, y que proyectan nueva luz sobre varios problemas teológicos, particularmente en el campo de la cristología y de la eclesiología: 1) primacía de Cristo en la intención de Dios al crear el mundo y cristocentrismo de la creación; 2) unificación sobrenatural de la humanidad en Cristo (nuevo aspecto del problema 'naturaleza-gracia'); 3) cristocentrismo-trinitario de la gracia, que tiene en Cristo su origen y su fin: participación en la vida intratrinitaria por Cristo; 4) valor salvífico de la encarnación, como apropiación personal de nuestra naturaleza humana por el Hijo de Dios: solidaridad de Cristo, por su misma constitución de Hijo de Dios hecho hombre, con toda la humanidad; 5) unión sacramental de lo divino con lo humano en Cristo, 'analogatum princeps' del sacramento y de los sacramentos de la Iglesia; 6) las tres funciones salvíficas de Cristo, como resultado de la unión de lo divino y de lo humano en él: Cristo, revelador supremo, sacerdote único, Señor; 7) la encarnación-muerte-resurrección como tres fases complementarias del devenir de un mismo misterio, el de la progresiva divinización de la humanidad de Cristo; 8) valor salvífico de la resurrección: importancia decisiva de la transformación divinizante del hombre Jesús y de su existencia celeste; 9) presencia operante de Cristo glorioso en la Iglesia por su Espíritu; 10) sentido escatológico de la creación y de la historia de la humanidad, determinado por la glorificación de Cristo". Se puede consultar J. Saraiva Martins, Gesù Cristo, en S. Garofalo, Dizionario del Concilio Ecumenico Vaticano Secondo, Roma 1969, col. 1184-1197.

(66) Porque la vida eterna, que estaba junto al Padre, se apareció a nosotros (1Jn 1, 2) (DV 1). Cf. Ignacio, Magnesios 6,1, en nota 42 de PO 7.

(67) GS 57. Cf. LG 36; DV 4. En GS 57, la iluminación es con la admirable Sabiduría, que desde la eternidad estaba con Dios, disponiendo todo con él, jugando en el orbe de la tierra, teniendo sus delicias con los hijos de los hombres (cf. Prov 8, 30s). Cristo es el que, existiendo en forma de Dios, se anonadó a sí mismo (Flp 2, 6) (LG 8).

(68) Nota 8 a AG 3.

(69) Cf. AG 15.

(70) LG 65.

(71) Cristo, a la vez que mediador, es la plenitud de la revelación (DV 2). Cf. LG 9; DV 7; DH 11; GS $22 ; 58$, etc. Lleva a su cumplimiento y perfecciona la revelación con toda su presencia y manifestación, especialmente con su muerte y resurrección, y finalmente con el envío del Espíritu de la verdad (DV 4). Verlo a él es ver al Padre. Respecto a Trinidad y revelación puede verse N. Silanes, Trinidad y Revelación en la 'Dei Verbum', Est Trin 17 (1983)143-214. 
encarnación caminó el Hijo de Dios para hacer a los hombres partícipes de la naturaleza divina, hecho por nosotros pobre, siendo rico, para que nosotros fuéramos ricos con su indigencia" (72). El final de este párrafo usa, pues, la categoría de intercambio, tan apreciada por Ireneo y los Padres, que, por así decirlo, pone el acento de nuestra salvación en la Encarnación. Y prosigue el texto: "Los Santos Padres proclamaron constantemente que no había sido sanado lo que no hubiere sido asumido por Cristo" (73). La naturaleza humana de Cristo, en la unidad de la persona del Verbo, fue instrumento de salvación (SC 5).

Y así el misterio del hombre solo se aclara verdaderamente en el misterio del Verbo encarnado, porque Adán era una figura del hombre futuro, Cristo (74). "Cristo, novísimo Adán, en la misma revelación del misterio del Padre y de su amor, manifiesta plenamente el hombre al mismo hombre y le descubre su altísima vocación... El que es imagen del Dios invisible, el mismo es hombre perfecto (75), que restituyó la semejanza divina a los hijos de Adán, deformada desde el primer pecado. Habiendo sido asumida en él la naturaleza humana, no destruida, por eso mismo también en nosotros fue transportada a dignidad sublime. Porque él, Hijo de Dios, por su encarnación de alguna manera se ha unido con todo hombre" (GS 22) (76). El Concilio en la nota 22 precisa que no hubo una transmutación del Verbo ni una transferencia de la carne a la naturaleza del Verbo (cita del concilio II de Constantinopla). Su carne animada, al ser deificada, no pereció, sino que permaneció en su propio estado y razón (cita del concilio III de Constantinopla) (77). Y en la nota siguiente añadirá que su voluntad humana, al ser deificada, no pereció (cita del concilio III de Constantinopla). Como vemos, en la Encarnación, citando los grandes concilios de la Antigüedad, el Vaticano II da la impresión de querer precisar el dogma, un poco más que lo que lo hace en la doctrina trinitaria. Esto serviría para indicarle al hombre que la unión con Dios no lo hace perecer, sino que lo plenifica. Cristo, pues, es el prototipo del hombre, y así es llamado hombre perfecto en GS 22 (78). Por eso "quienquiera siga a Cristo, hombre perfecto, el mismo se hace más hombre" (GS 41).

Así como la unión o unidad de las personas divinas es aludida dos veces como prototipo de la unión de la Iglesia y de los hombres, así también la Encarnación va

(72) Cf. 2Co 8, 9; PC 13; PO 17, etc

(73) El texto continúa diciendo que asume la naturaleza humana íntegra. A este respecto pone el Concilio una cita textual de Agustín en la nota 15, donde este precisa que el Espíritu no nos redimió porque no se encarnó.

(74) GS 22. Véase LG 1; GS 10

(75) Cf. LG 2

(76) Véase SC 83.

(77) Finalmente, en esa misma nota remite a la fórmula de Calcedonia: "Hay que reconocerlo en dos naturalezas, sin confusión, sin mutación, sin división, sin separación”. Según LG 66, se adora al Verbo de Dios encarnado, junto con el Padre y el Espíritu Santo.

En la Eucaristía se contiene el pan vivo que da la vida a los hombres por medio de la carne de Cristo, vivificada por el Espíritu Santo y vivificante. "Carne vificante" es una expresión apreciada por Cirilo de Alejandría (DH 262). En PO 5 dirá el Concilio que a través de su humanidad, Cristo infunde continuamente la vida divina.

(78) Cf. GS 38; 41; 45. En Cristo apareció el hombre nuevo, creado según Dios, en el que se revela la caridad de este (AG 12). Véase AG 8. 
a ser aludida como semejanza de la expresión de la palabra de Dios en lenguas humanas, de la naturaleza de la Iglesia en la unión de lo divino y humano, de cómo la Iglesia debe insertarse en los diversos grupos y asumir la riqueza de las culturas a las que es enviada. Según DV 13, las palabras de Dios, expresadas en lenguas humanas por condescendencia admirable de Dios con nuestra naturaleza de hombres, se hicieron semejantes al lenguaje humano, como en otro tiempo el Verbo eterno del Padre, habiendo asumido la carne de la humana debilidad, se hizo semejante a los hombres. Según LG 8, la unidad compleja de la Iglesia, constituida por el elemento humano (trabazón visible, sociedad con órganos jerárquicos, junta visible, terrestre) y por el elemento divino (comunidad de fe, esperanza y caridad; cuerpo místico de Cristo; comunidad espiritual; con bienes celestes) se asemeja, con analogía (79) no mediocre, al misterio del Verbo encarnado. Porque así como la naturaleza asumida sirve al Verbo como instrumento vivo de salvación, unido indisolublemente a él, de manera no desemejante el organismo social de la Iglesia sirve al Espíritu Santo, que la vivifica para aumento del cuerpo (80). Según AG 10, la Iglesia, para ofrecer a todos el misterio de la salvación, debe insertarse en los grupos, a los que pertenecen miles de millones de hombres de antiguas religiones, o que permanecen extraños al conocimiento de Dios, con el mismo movimiento, por el que el mismo Cristo con su encarnación se ató a ciertas condiciones sociales y culturales de los hombre con que vivió. Según AG 22, al modo de la economía de la Encarnación, las Iglesias jóvenes asumen todas las riquezas de las naciones que han sido dadas en herencia a Cristo (81).

(79) El vocablo analogia solo es empleado otra vez, en DV 12, para la analogía de la fe en relación a la interpretación de la Escritura.

(80) Véase SC 2. Puede verse J. Alfaro, Christus, sacramentum Dei Patris, Ecclesia sacramentum Christi gloriosi, en A. Schönmetzer (ed.), Acta Congressus Internationalis de theologia concilii Vaticani II, Romae diebus 26 septembris-1 octobris 1966 celebrati, Vaticano 1968, pp. 4-9. El mismo Alfaro (Cristología y antropología..., 118s) dice lo siguiente: "La doctrina eclesiológica del concilio Vaticano II está orientada por la fecunda intuición de la analogía del misterio de la Iglesia con el misterio fundamental del cristianismo, la encarnación del Hijo de Dios: la Iglesia no es inteligible sino como la proyección del misterio de Cristo en la familia humana. La expresión y comunicación de la gracia de Dios en la estructura visible de la Iglesia se funda en la revelación y comunicación suprema de Dios en el hombre Jesús, su Hijo. En Cristo ha quedado encarnada para siempre la gracia de Dios, es decir, ha adquirido definitivamente expresión y transmisión humana. La naturaleza corpóreo-espiritual del hombre (en su triple apertura hacia Dios, los demás hombres y el mundo) ha sido elevada a revelación-realización del amor salvífico de Dios. Cristo es constitutivamente el sacramento de Dios, porque en él la gracia divina (que es Dios mismo en su personal autocomunicación) se ha apropiado lo humano como signo-instrumento de su soberana potencia. La Iglesia es el sacramento de Cristo glorioso, que con su presencia supratemporal y supraespacial la ha constituido en signo de su gloria e instrumento transmisor de su vida... Al transformar internamente el corazón del hombre, la gracia de Dios se apropia lo humano, adquiere una dimensión humana, se 'encarna', se expresa y se comunica por lo humano. Toda realización de la gracia de Dios en el hombre es una sacramentación de la misma. La gracia se apropia de lo humano para divinizarlo; solamente apropiándoselo, lo diviniza". Después añade: "Como unión personal del Hijo de Dios con la naturaleza humana, la encarnación es el fundamento supremo de la unidad de la comunidad humana, destinada en Cristo a la unión inmediata con Cristo mismo y en él con Dios en su misterio personal. Pero la encarnación tiene su fundamento en la Trinidad; por eso la unidad de los hombres en Cristo se basa definitivamente en la comunión de vida trinitaria, cuyo manantial es el Padre" (Ib, 124). El interesante libro de H. Mühlen, Una Mystica Persona. Die Kirche als das Mysterium der heilsgeschichtlichen Identität des Heiligen Geistes in Christus und den Christen. Eine Person in vielen Personen, Paderborn 1968, 3a ed., que trata profusamente de ese texto, no me convenció del todo.

(81) Como la palabra de Dios que fructifica absorbiendo, transformando y asimilando la savia 


\section{LA PASCUA}

Pero el Concilio no destaca tanto la Encarnación como la Pascua, la muerte y resurrección de Jesús. Aquí, fijándome solo en algunos vocablos, destaco, como muestra, que los vocablos pascha y paschalis aparecen unas 28 veces, y mors, mortuus, aplicado a la muerte de Cristo, unas 52 veces, a las que habría que añadir unos 11 usos independientes de passio y passus. Por el bautismo los hombres se insertan en el misterio pascual de Cristo: co-muertos, co-sepultados, co-resucitados (82). El cristiano debe asociarse al misterio pascual. Así configurado a la muerte de Cristo, andará al encuentro de la resurrección robustecido por la esperanza. "Porque habiendo Cristo muerto por todos... debemos sostener que el Espíritu Santo a todos ofrece la posibilidad de asociarse a este misterio pascual de un modo solo conocido por Dios" (GS 22). Del costado de Cristo que duerme en la cruz surgió la Iglesia (83). La gracia divina mana del misterio pascual de la pasión, muerte y resurrección de Cristo, de donde sacan su fuerza todos los sacramentos y sacramentales (84). La Iglesia sigue anunciando en la Eucaristía (85) la muerte del Señor hasta que venga (86). Y cada vez que se celebra el sacrificio de la cruz en el altar, en el cual 'Cristo, nuestra pascua, es inmolado' (1Co 5, 7) se ejerce la obra de nuestra redención (87). En la Eucaristía se contiene todo el bien espiritual de la Iglesia (88), el mismo Cristo, nuestra pascua, pan vivo, que, mediante su carne vivificada por el Espíritu y vivificante, da la vida a los hombres (89). Es el viático para el camino y las arras de la esperanza (90).

\section{LA MISIÓN DE CRISTO}

Detengámonos un poco más en la misión de Cristo. El Verbo, por quien todo fue hecho, se hizo él mismo carne para salvar a todos y recapitular el universo, como hombre perfecto (91). No entraré en los diversos vocablos y categorías con que se expresa la salvación (92). La recapitulación corresponde al designio de amor

(82) SC 6. Cf. SC 104; LG 7; UR 22; AG 14, etc.

(83) SC 5

(84) SC 61. Todas las cuales cosas, que manan de la pascua de Cristo, serán consumadas en su venida (PO 2). Véase NA 4.

(85) Memorial de la muerte y resurrección del Señor (AG 14). Cf. SC 47; UR 22; PO 4; 13

(86) SC 6. Véase LG 8.

(87) LG 3. Cf. SC 2. En el sacrificio eucarístico se perpetúa el sacrificio de la cruz (SC 47). Cf. SC 7; LG 28; PO 2, etc. En la conmemoración de los misterios de la redención, los fieles entran en contacto con ellos y se llenan de la gracia de la salvación (SC 102; cf. 35). Véase AG 13.

(88) Fuente y culmen de toda evangelización (PO 5). Cf. LG 11; CD 30; PO 14, etc. Es tal la importancia de la Eucaristía, que el Vaticano II usa eucharistia y euchariticus 69 veces, reservando normalmente para los aspectos más prácticos la palabra missa (46 veces). 10 veces habla de la Cena del Señor. Véase GS 38.

(89) PO 5.

(90) GS 38. Cf. SC 47.

(91) GS 45. Cf. GS 57.

(92) Respecto a los títulos cristológicos, en general, puede consultarse Silanes, "La Iglesia de la Trinidad", 307ss. 
del Padre, de instaurar todo en Cristo (Ef 1, 10) (93). Y así la Iglesia tiende a recapitular toda la humanidad con todos sus bienes, bajo Cristo cabeza (94) en la unidad del Espíritu (95), para gloria del creador del universo y Padre (96). El Padre preconoció y predestinó a los elegidos a ser conformes a la imagen de su Hijo, para que este fuera el primogénito entre muchos hermanos $(\mathrm{Rm} 8,29)(97)$. Es el primogénito de toda creatura $(\mathrm{Col} 1,15)(98)$. Porque a aquel, por el que hizo los siglos, el Padre lo constituyó heredero de todo para instaurar todo en él (99). En él nos eligió y predestinó para la adopción de los hijos (cf. Ef 1, 4s.10) (100). La instauración perfecta será al final, en la restitución de todo (101).

\section{JESÚS Y LA FUNDACIÓN DE LA IGLESIA}

Si vamos a la vida de Jesús, no hay referencia a los problemas de su conciencia mesiánica y, salvo la rápida alusión de DV 19, tampoco al Jesús histórico. Es una cristología de arriba (102), es el enviado del Padre. Me atrevería a decir que el Jesús del Vaticano II se acerca a una visión alejandrina. Hay dispersas y variadas alusiones a sus enseñanzas y a su ejemplo. Se insiste en que no vino a ser servido, sino a servir y dar su vida, siguiendo a Mc 10, 45 (103), lo que nos impulsa hacia una Iglesia (y cristianos) servidora. También cita el himno de Flp 2, 6ss sobre el anonadamiento (104). Entre otras referencias a su vida, en LG 57s recorre los pasajes en que interviene María, y en LG 46 las diversas facetas de Cristo que se muestran a través de los religiosos; en DH 11 muestra el respeto de Jesús por la libertad de la fe de sus auditores; en GS 32 presenta a Jesús en su relación social y solidaria. Pero el tema grueso es la fundación de la Iglesia. Cristo es el fundador (105). Antes de ascender al cielo (106), la funda como sacramento de salvación (107). Jesús llama y envía a los

(93) GS 45 .

(94) En AG 3 es llamado cabeza de la humanidad renovada.

(95) LG 13.

(96) LG 17

(97) Silanes ("La Iglesia de la Trinidad") destaca la conexión de esto con la "familia Dei", a la que dedica el cap. 4.

(98) LG 2. Cf. LG 63; GS 10; 22; 32.

(99) AG 3. Cf. GE prooem; AA 7.

(100) LG 3.

(101) LG 48

(102) Cf. Silanes ("La Iglesia de la Trinidad”, 307).

(103) LG 5; OT 4; DH 11; AG 3. Cf. LG 27; GS 3.

(104) LG $8 ; 36 ; 42 ;$ PC $1 ; 5 ; 14 ;$ AG 24.

(105) P. e.: IM 3; LG 5 (Jesús realizó el inicio de su Iglesia predicando la venida del reino de Dios); 8; 9; 19; UR 1; AG 1; GS 3 (el Espíritu es el que la conduce); 40 (la Iglesia procede del amor del Padre eterno, es fundada en el tiempo por Cristo Redentor y reunida en el Espíritu Santo); 76. Alfaro (Cristología y antropología, 130) opinará en una reflexión teológica neotestamentaria: "El Cristo histórico funda la Iglesia en sus estructuras sociales-visibles... El Cristo glorificado funda la Iglesia en el aspecto invisible de su eficacia salvífica; es el resucitado el que da su Espíritu a la Iglesia como principio interno de vida divina. La identidad del Cristo glorioso con el Cristo histórico funda la unidad de la Iglesia en su aspecto visible y en su función salvífica".

(106) La Iglesia, constituida en los últimos tiempos, efundido el Espíritu fue manifestada (LG 2; cf. 59).

(107) AG 5 (habiendo una vez para siempre cumplido en sí mismo los misterios de nuestra salvación y de la renovación de los mundos, y alcanzado toda potestad). Sobre el alcance histórico de la 
apóstoles, como él había sido enviado; instituye la Cena (108); de su costado en la cruz surge la Iglesia; resucitado le da su Espíritu, con lo que la hace su cuerpo (109); la constituye con su jerarquía, la quiere una (110). Siendo él el único salvador (111), la Iglesia tiene una misión universal: es el sacramento universal de salvación (112).

\section{EL CRISTO GLORIOSO Y LA IGLESIA}

Creo que la visión fundamental sobre Cristo del documento es la del resucitado (113), que es la cabeza del cuerpo, que es la Iglesia (114), de donde le viene a esta el crecimiento, la vida (115). Es el esposo (116). Cristo tiene el triple oficio de

afirmación de la Iglesia como sacramento, puede verse G. L. Müller, Das trinitarische Grundvertändnis der Kirche in Kirchenkonstitution 'Lumen Gentium”, MThZ 45 (1994) 451-465.

(108) P. e. SC 47.

(109) Habiendo resucitado, infundió su Espíritu vivificante en los discípulos y mediante este constituyó su cuerpo, que es la Iglesia, como sacramento universal de salvación (LG 48). Cf. LG 7; 39; UR 2; GS 32; 78. Véase LG 5; 9; 21; 24; DV 17. Cristo siempre está presente a su Iglesia y se la asocia (cf. SC 7).

(110) Insistido en UR.

(111) P. e., fuera de él no hay salvación (cf. Hch 4, 12: AG 7; GS 10). Sobre la relación entre Cristo único salvador y la necesidad de la Iglesia, cf. p. e. LG 14; AG 7.

(112) LG 48; AG 1; GS 45. Cf. SC 5; LG 1; 9; 59; GS 42.

(113) Está sentado a la diestra del Padre como ministro del santuario y tabernáculo verdadero (SC 8) y opera continuamente en el mundo (LG 48). Estará con nosotros hasta la consumación del mundo (Mt 28, 20) (LG 17). J. Alfaro afirma (Cristología y antropología..., 108s): "Queda así fuertemente subrayada la importancia de la transformación divinizante del hombre Jesús en la resurrección; entonces Cristo pasó a ser 'el Señor' por la participación en la gloria y en la potencia misma de Dios. Por primera vez en un documento del magisterio la glorificación de Cristo y su existencia en la eternidad divina (más allá del tiempo y del espacio) alcanza todo el significado salvífico que la fe de la Iglesia le ha reconocido. El concilio Vaticano II ve todo el misterio de la salvación de la humanidad en la Iglesia a la luz de la existencia gloriosa de Cristo: la eterna presencia de Cristo glorioso junto al Padre se hace presente y visible en la Iglesia, cuya vida está escondida con Cristo en Dios. La liturgia de la Iglesia es una participación en la liturgia celestial, cuyo eterno y único sacerdote es Cristo: eternizando su propia oblación, ofrece Cristo a Dios la única verdadera adoración y a través de ella llega al trono del Altísimo el culto litúrgico de la Iglesia. De la presencia eterna de Cristo glorioso junto al Padre proviene toda la eficacia santificadora de la Iglesia en sus sacramentos: es el resucitado, quien en el sacramento y en los sacramentos de la Iglesia actúa el poder santificador, que ha recibido de Dios en la glorificación de su humanidad. El sacerdocio invisible de Cristo glorificado es el manantial escondido de toda la gracia, que es comunicada por la estructura visible de la Iglesia".

(114) 23 veces (16 en LG) hablaría el Vaticano II de Cristo como cabeza en relación a su cuerpo, que es la Iglesia; y dos veces (LG 13 y 17) con un alcance más universal. Cabeza va con pastor en LG 28; PO 6.

(115) De él dimana, como de fuente y cabeza, toda la gracia y vida del pueblo de Dios (LG 50). El cuerpo crece desde la cabeza (LG 30; cf. 6; 7; véase 8) y hacia ella (LG 7). Para que incesantemente nos renovemos en él, afirma LG 7, nos dio de su Espíritu, que existe uno y el mismo en la cabeza y en los miembros. Él es la piedra angular (LG 6; 19; UR 2; 18; AG 9). A través de su humanidad infunde continuamente vida divina en los miembros de su cuerpo (PO 5). "Por la grandeza de su poder domina sobre lo celestial y lo terrestre y por su supereminente perfección y operación llena todo su cuerpo con las riquezas de su gloria (cf. Ef 1, 18-23) (LG 7). Y el presbítero, por su íntima unión con él, puede llegar a decir: Cristo vive en mí (Ga 2, 20) (PO 12). Llena a su Iglesia con sus dones divinos (LG 7), la fortalece (LG 8), etc. Véase AA 4.

(116) 25 veces aparece sponsus o sponsa, respecto a la relación entre Cristo y la Iglesia. La Iglesia va creciendo hasta la medida de la plenitud de Cristo (cf. Ef 4, 13) (SC 11; AG 9; PO 22). Véase PC 14; GE 2. 
sacerdote (117), maestro (profeta) y rey (118), en el que participa todo su cuerpo, pero obispos y presbíteros de una manera especial: son representantes de Cristo cabeza (119); actúan in persona Christi (120). Cristo tiene diversas presencias en su Iglesia (121) y se sirve de sus ministros como de instrumentos (122). Ininterrumpidamente ejerce en la liturgia su rol sacerdotal, siendo los presbíteros sus ministros (123). Cristo, sumo y eterno sacerdote es el que ofrece el sacrificio de la Eucaristía por medio de ellos. "Está presente en el sacrificio de la misa, tanto en la persona del ministro, 'ofreciéndose ahora por el ministerio de los sacerdotes el mismo que entonces se ofreció en la cruz' [DH 1743], cuanto sobre todo bajo las especies eucarísticas" (SC 7) (124). El culto público al Padre es oficiado por Cristo y la Iglesia, por la cabeza con su cuerpo (125). Cristo volverá en gloria para el final. En esta visión de Cristo creo que influye el que el Concilio está centrado en la Iglesia y comenzó por la liturgia como su primer documento aprobado.

\section{EL ESPÍRITU SANTO}

El vocablo Spiritus se aplica unas 266 veces al Espíritu Santo en el Vaticano II (126). Llama la atención lo poco que aparece la expresión Spiritus Dei (127). A esto se junta que casi nunca aparece Dios (el Padre) enviando o dando el Espíritu (128).

(117) Respecto a Cristo se usan sacerdos, sacerdotalis y sacerdotium unas 33 veces. Pontifex se le aplica 3 veces.

(118) P. e.: LG 13; 21; 31; OT 4; AA 2; PO 1. Véase LG 22, etc. 19 veces Cristo es llamado pastor.

(119) Por el sacramento del Orden los presbíteros son configurados a Cristo sacerdote, como ministros de la cabeza para construir todo su cuerpo, que es la Iglesia (PO 12). Cf. LG 28; PO 6

(120) Los presbíteros, configurados a Cristo sacerdote, actúan en la persona de Cristo cabeza (PO 2). Cf. lo dicho supra respecto al uso del vocablo persona.

(121) Cf. p. e. SC 7. Según LG 26, Cristo se hace presente con su poder y da unidad a la Iglesia. Puede verse K. Rahner, De praesentia Domini in communitate cultus: synthesis theologica, en A. Schönmetzer (ed.), Acta Congressus Internationalis de theologia concilii Vaticani II, pp. 330-338.

(122) Cf. p. e. PO 12. Véase LG 21; 35; PO 14.

(123) PO 5.

(124) Cf. PO 2. Los presbíteros, sacerdotes a imagen de Cristo, realizan el culto eucarístico representando la persona de Cristo; unen los votos de los fieles al sacrifico de Cristo su cabeza, y representan y aplican en el sacrificio de la misa el único sacrifico de Cristo, que una vez para siempre se ofrece al Padre como hostia inmaculada (LG 28). Véase PO 5.

(125) SC 7. Toda celebración litúrgica es obra de Cristo sacerdote y de su cuerpo (SC 7). Cf. p. e. SC 83; 84. La Iglesia, por la voz de los presbíteros en el oficio divino, persevera en la oración junto con Cristo, siempre vivo para interceder por nosotros $(\mathrm{Hb} 7,25)$ (PO 13).

(126) En SC, documento inicial, es solo seis veces. En NA no aparece (ni en IM). Según Silanes (" $L a$ Iglesia de la Trinidad”, 395), "La novedad más saliente del Vaticano II, consecuencia del nuevo planteamiento de la eclesiología, ha sido el redescubrimiento de la persona y acción del Espíritu Santo en la Iglesia". Según este mismo autor en su artículo Trinidad y Revelación en la 'Dei Verbum, p. 213, "el Concilio ha dejado más bien apuntada que desarrollada la pneumatología, en concreto, la misión del Espíritu Santo en la revelación”. Sobre el Espíritu en Vaticano II, puede también verse F. Tommaso, Spirito Santo, en S. Garofalo (ed.), Dizionario del Concilio Ecumenico Vaticano Secondo, Roma 1969, col. 1867-1886.

(127) Esta expresión solo aparecería unas cuatro veces, tres de ellas en GS. Espíritu del Señor aparece en AG 3; PO 17; 22; GS 11; 39. Cf. GS 22. Tampoco hay referencia directa al Espíritu en relación a la creación. Véase PO 22; GS 11; 26. Pero, por el Espíritu Santo el hombre es hecho nueva creatura (LG 56; GE 2; GS 37; cf. LG 7).

(128) Cf. p. e. LG 13 (el Espíritu de su Hijo); 59 (prometido por Cristo). Pero en el Espíritu habita Dios en su Iglesia (SC 2; LG 6; PO 22). Igualmente hay otras actuaciones de Dios mediante el Espíritu. 
Este es el de Cristo, quien lo envía, derrama, da, etc. (129). El Espíritu actúa como una persona (130), pero, sin embargo, tiene un rostro menos configurado que el Padre y el Hijo (131). Así el Espíritu sopla donde quiere (Jn 3, 8) (132). Como el Espíritu viene de Jesús glorificado, es dado en Pentecostés. Pero, con todo, también ha actuado antes de su glorificación (133). El Paráclito, el Espíritu de la verdad, continúa la obra de Cristo (134), pero también actuó en Cristo, en su encarnación (135), en su vida. Pese a que es Cristo quien da el Espíritu, este lo ha ungido a él (136). Así Cristo hace participe a todo su cuerpo místico de la unción que él recibió (137). Su carne es vivificada y vivificante por el Espíritu Santo (138). Y el Dios del Espíritu que habita en nosotros, que resucitó a Cristo, nos resucitará también a nosotros mediante su Espíritu (Rm 8, 11) (139).

Si Cristo hizo la obra de la redención, el Espíritu tiene que extenderla, aplicarla (140). Es el que inspiró las Escrituras (141), el que conduce la tradición viva (142), el que impulsa hacia la fe (143) y lleva a la verdad plena (144). Gracias a él nace la nueva creatura (145). Es el que transforma, santifica (146). En LG 4, el Concilio declara que es enviado para santificar y conducir hacia el Padre. Es el Espíritu de adopción en el que clamamos abba (147). Inhabita en los corazones (148), donde difunde la caridad de Dios (Rm 5, 5) (149). Es el gran don de Cristo. Mediante él, constituye su cuerpo, como

(129) Según AG 4, lo envía de parte del Padre; y según LG 5, derramó el Espíritu prometido por el Padre.

(130) Cf. p. e. UR 7; GS 26. Véase UR 21.

(131) Así, por ejemplo, sin alusión a Jn 17, 3, el anuncio en la misión es del Dios vivo y de su enviado, para salvación de todos, Jesucristo. El Espíritu Santo es el que abre los corazones de los no cristianos para que se conviertan (AG 13). Véase p. e. LG 15; GS 21.

(132) AA 3; PO 13

(133) AG 4. Según una cita de San León Magno, en Pentecostés hubo una añadidura de liberalidad a lo que ya estaba incoado; hubo otra medida.

(134) Cf. p. e. LG 48; GS 3.

(135) LG 52;59;63;65; AG 4.

(136) SC 5; AG 3; PO 17.

Pero la procesión del Espíritu no aparece como condicionante de la generación de este en la Trinidad inmanente. Tampoco aparece el Espíritu como culminación perfectiva de la Trinidad.

(137) PO 2. Véase AG 4: este texto compara la venida del Espíritu Santo en la Anunciación y sobre Cristo que reza, con la venida en Pentecostés donde comienzan los hechos de los Apóstoles.

(138) PO 5.

(139) GS 22. Véase LG 4.

(140) Cf. p. e.: LG 4; 48; AG 3 y 4 . Véase GS 3.

(141) DV 7; 9; 11; 18; 20. Los apóstoles predicaron lo que recibieron de Cristo o aprendieron del Espíritu que sugería (DV 7). Véase DV 17; 19; 21.

(142) Cf. LG 25; DV 8; 9; 10; 12.

(143) DV 5; AG 13; 15. Véase LG 19.

(144) Cf. LG 4; 12; DV 5; 8; 20; 23. Véase GS 15; 44. El suscita y sustenta el sensus fidei (LG 12). Asiste a los sucesores de Pedro en las definiciones infalibles y es obra del Espíritu que el asenso de la Iglesia nunca les falte (LG 25). Hay una luz del Espíritu (cf. p. e. LG 25; DV 9; GS 10). Este enseña (cf. p. e. LG 53; DV 23).

(145) Además de lo antes dicho, véase, en este respecto, p. e.: LG 9; 11; 64; AG 7; 15. Por la unción del Espíritu Santo los bautizados son consagrados como casa espiritual y sacerdocio santo (LG 10). Cf. LG $12 ; 34$. Véase PO 2; 12.

(146) P. e.: LG 12; 15; CD 1; AG 23; PO 2. Santifica por el ministerio y los sacramentos (LG 12; AA 3). Cf. G. Chantraine, op. cit., 998 ss.

(147) SC 6. Véase AG 14; GS 22.

(148) LG 4; 9. Véase GS 22. Y permanece para siempre (UR 2).

(149) LG 42; UR 24; PC 1; 15; AA 4. Cf. LG 40; AA 3; GS 78. 
vimos antes. El Cristo exaltado actúa en su Iglesia mediante su Espíritu (150). El Espíritu es como el alma de la Iglesia (151). Él la conduce (152). El Espíritu unifica (153), en la diversidad (154). El Espíritu vivifica (155), renueva (156), fortalece (157).

Da a la Iglesia sus dones jerárquicos y carismáticos (158).

"El es el Espíritu de la vida o la fuente de agua que salta hasta la vida eterna (cf. Jn 4,$14 ; 7,38$ s) por quien el Padre vivifica a los hombres muertos por el pecado, hasta que resucite sus cuerpos mortales en Cristo (cf. Rm 8, 10s). El Espíritu habita en la Iglesia y en los corazones de los fieles como en un templo (cf. 1 Co 3,$16 ; 6,19$ ) y en ellos ora y da testimonio de la adopción de los hijos (cf. Ga 4, 6; Rm 8, 15s y 26). A la Iglesia, a la que conduce a toda verdad (cf. Jn 16,13) y unifica en la comunión y ministerio, la dota y dirige con diversos dones jerárquicos y carismáticos y la adorna con sus frutos (cf. Ef 4, 11s; 1Co 12, 4; Ga 5, 22). Hace rejuvenecer la Iglesia con la fuerza del Evangelio y perpetuamente la renueva y la conduce a la unión consumada con su esposo. Porque el Espíritu y la Esposa dicen al Señor Jesús: ¡Ven! (Ap 22, 17)” (LG 4).

\section{CRISTO Y EL ESPÍRITU}

Veamos algunas distinciones entre la acción de Cristo y la del Espíritu, como ejemplos. El hombre fue redimido por Cristo y hecho nueva creatura en el Espíritu Santo (159). La Iglesia es fundada por Cristo y conducida por el Espíritu (160). Los

(150) P. e.: LG 34; AG 4; PO 5; 16; GS 10. El resucitado, investido de todo poder, ya opera en el corazón de los hombres por la virtus de su Espíritu Santo (GS 38). Según CD 1, Cristo santificó a los apóstoles entregándoles el Espíritu para que ellos glorifiquen al Padre (cf. LG 21).

(151) LG 7 (respecto a la historia de este texto, cf. Silanes, "La Iglesia de la Trinidad", 378-381; véase la reflexión de Silanes, "La Iglesia de la Trinidad", 403ss); AG 4. El Cristo que dispuso el ministerio, prometió el Espíritu para que ambos se asocien en la obra de la redención (AG 4). Cf. p. e. LG 8. Véase LG 9; PO 15. Respecto a la relación del Espíritu Santo con la apostolicidad y catolicidad de la Iglesia, véase, Chantraine, op. cit., 996-998.

En cuanto se ama a la Iglesia, en tanto se tiene el Espíritu, en palabras de Agustín (OT 9).

(152) P. e.: LG 12; 13; PO 12; 13; 15; 22; GS 1;3; 11; 21; 43. Véase LG 20; 41; 42; UR 2; CD 2; PC 1; AA 23; AG 4; 17; PO 6;17; 18. La Iglesia por la virtud del Espíritu Santo permanece fiel esposa del Señor y siempre ha sido signo de salvación (GS 43).

(153) Cf. p. e.: LG 7; 13; 22; 50; UR 4; 7; AG 15; GS 42; 45; 92. Según AG 4, unifica en la comunión y en el ministerio. Tan íntimamente une a todos en Cristo, que es principio de la unidad de la Iglesia (UR 2). Es el mismo en la cabeza y en los miembros (LG 7).

(154) P. e. LG 7; 32; AG 4. Véase UR 2; PC 8.

(155) Cf. LG 4; 7; 8; 13; 34; 48; UR 2; AA 29; AG 4; PO 12; GS 45.

(156) P. e. LG 4; 9.

(157) P. e.: LG 11; 19; 64; OE 30; CD 12; AG 11; 24; GS 10; 38. Opera admirablemente con potencia infinita (LG 44; cf. GS 92). Impulsa (p. e.: LG 17; 39; 40; 45; UR 24; PC 2; 14; AA 29; 33; AG 4; $5 ; 23 ; 24 ;$ PO 18; 22; GS 92). Véase OT prooem; AG 40; PO 11. Libera para que se proyecten hacia el futuro (GS 38). Según Philippon (op. cit., 355), "El Espíritu Santo es el Inspirador, el Motor inicial y el Realizador supremo de todas las actividades jerárquicas en la Iglesia de Cristo".

(158) Cf. LG 7; 12; UR 3; AG 4. Véase UR 2; CD 2; AA 3; 4; 30; AG 23; GS 38; 45; 93. Produce frutos (p. e. LG 34; 39; 40)

(159) GS 37. "El hombre cristiano, hecho conforme a la imagen del Hijo, que es primogénito entre muchos hermanos, recibe las 'primicias del Espíritu' ( $\mathrm{Rm} 8,23)$, con las que es hecho capaz de cumplir la nueva ley del amor. Por este Espíritu, que es 'prenda de la herencia' (Ef 1, 14), es restaurado todo el hombre interiormente, hasta la 'redención del cuerpo' (Rm 8, 23)" (GS 22).

(160) P. e. GS 3; 40 (reunida). Los obispos predican bajo la autoridad de Cristo e ilustran bajo la luz del Espíritu (LG 25). El Espíritu conserva la forma de gobierno establecida por Cristo (LG 27). 
presbíteros son sellados por la unción del Espíritu Santo y configurados a Cristo sacerdote (161). Los presbíteros son enviados por Cristo y consagrados por el Espíritu (162). Los laicos, fortalecidos en la confirmación por el Espíritu Santo, son destinados para el apostolado por el mismo Señor (163). En DH 15 expresa el deseo de que el Padre haga que toda la familia humana sea conducida a la 'libertad de la gloria de los hijos de Dios' (Rm 8,21) por la gracia de Cristo y la virtus del Espíritu Santo (164). Como ya vimos, la vuelta al Padre es en el Espíritu, por Cristo, único mediador (165). En resumen, la misión de Cristo está indisolublemente unida a la del Espíritu (166).

\section{ACCIÓN DEL ESPÍRITU FUERA DE LA IGLESIA VISIBLE. ACTUACIONES ESPECIALES EN ESTE TIEMPO DE LA IGLESIA}

El Espíritu también actúa fuera del recinto de la Iglesia, porque Dios a todos ofrece su salvación (167). Actúa en las Iglesias y comunidades cristianas separadas (168), actúa en otras religiones (169). Llama a la fe por medio de las semillas del Verbo y la predicación del Evangelio (170). El empeño por promover y reformar la liturgia es calificado como un paso del Espíritu por su Iglesia (171). A él se debe el nuevo dinamismo del movimiento ecuménico (172), la mayor participación y toma de conciencia de los laicos en la Iglesia (173). Está presente en la evolución de la humanidad respecto al orden social en bien del hombre y su dignidad (174). En relación al Espíritu, tenemos que estar, por tanto, atentos a los signos de los tiempos, de las providenciales disposiciones de Dios (175). Se nos pide no prejuzgar los impulsos futuros del Espíritu en el ecumenismo (176).

(161) PO 2. Los critianos estamos unidos a Cristo en la Iglesia y sellados en el Espíritu Santo, prenda de nuestra herencia (Ef 1, 14) (LG 48).

(162) PO 12. Véase CD 2; OT 2.

(163) AA 3. Véase AG 23.

(164) Muchas veces habla el Concilio de la gracia del Espíritu Santo (cf. p. e.: LG 11; 21; OE 25; UR 1; 4; OT 10; AG 5; véase LG 39).

(165) 13 veces habla el Vaticano II del único mediador o única mediación.

(166) De ambas misiones toma su origen la Iglesia (AG 2). Respecto a AG 2-5, puede verse J. B. Anderson, A Vatican II Pneumatology of the Pachal Mistery. The Historical-Doctrinal Genesis of Ad Gentes 1, 2-5 (Analecta Gregoriana, 250), Roma 1988.

(167) Cf. GS 22. Véase GS 41; 93.

(168) Cf. LG 15; OE 25; 30; UR 3; 4; GS 92.

(169) Cf. GS 92

(170) AG 15. Cf. LG 19; AG 13.

(171) SC 43.

(172) UR 1. Véase LG 15; OE 25.

(173) AA $1 ; 33$.

(174) GS 26.

(175) Cf. SC 43; UR 4. Cf. AA 14; 16; PO 9; 18.

(176) UR 24 


\section{PALABRAS FINALES}

Podemos concluir que el Espíritu nos parece estar bastante destacado en los documentos conciliares (177), equilibrando así el cristocentrismo (178). Se trata del Espíritu en la economía, en su misión. Salvo UR 2, no habría alusión al Espíritu como vínculo de unidad entre el Padre y el Hijo, o como amor y don mutuo en la Trinidad inmanente (179). Es, pues, un concilio de la Trinidad económica y por ser tal, el Padre aparece como fuente y término de la actividad salvífica, que es por Cristo y en el Espíritu (180). Se atiene mucho al lenguaje del Nuevo

(177) Según Pablo VI, "a la cristología, y especialmente a la eclesiología del Concilio, debe suceder un estudio nuevo y un culto nuevo sobre el Espíritu Santo justamente como complemento que no debe faltar a la enseñanza del Concilio" (audiencia general del 6 de junio, en Ecclesia, 16 de junio de 1973, p. 5; cf. Id., Marialis Cultus, 27). Según Y. Congar (Actualité de la pneumatologie, p. 16, en Credo in Spiritum Sanctum. Atti del Congreso Internazionale di Pneumatologia. I, Vaticano 1983, pp. 15-28), "el segundo concilio del Vaticano ha comenzado a devolvernos la dimensión pneumatológica de la Iglesia, en ella misma e inseparablemente en su relación con el cosmos". Véase N. Silanes, El Espíritu Santo y la Iglesia en el concilio Vaticano II, pp. 1019ss, en Credo in Spiritum Sanctum. II, pp. 1011-1024.

B. J. Hilberath, en su libro Pneumatologie (Düsseldorf 1994), p. 157s, afirma los siguiente: "La eclosión se logra con el pontificado de Juan XXIII (1958-1963), que espera para la Iglesia un nuevo Pentecostés. Y, así, el Concilio Vaticano II, convocado por él, debe valorarse ante todo como un acontecimiento espiritual que desencadenó numerosos procesos de conversión y renovación. En el contexto de la temática eclesiológica recibida como herencia del Concilio Vaticano I, se llega, en confrontación crítica con los esquemas presentados, a través de los contactos con teólogos orientales, y en virtud de la inserción de la teología renovada bíblica y patrística, a plantearse de múltiples maneras la dimensión pneumática de la Iglesia, aunque no pueda hablarse de una sistemática sostenida. La historia de la composición de la Constitución sobre la Iglesia así como una comparación con la Constitución sobre la liturgia, aprobada con anterioridad, da testimonio de este proceso teológico espiritual. De este modo, la eclesiología fuertemente cristocéntrica, orientada por el modelo de la encarnación, adquiere un contrapeso pneumatológico en el marco de la eclesiología-communio orientada según la vida del Dios trino y uno (...). Sobre todo los obispos de las Iglesias orientales unidas con Roma hacen que se recuerde el contexto pneumatológico del tercer artículo del Credo y que el tiempo de la Iglesia es el tiempo del Espíritu Santo. Ante el trasfondo del Vaticano I, adquiere una singular importancia el artículo 12, vivamente discutido, de la Constitución sobre la Iglesia: La totalidad de los creyentes participa en el ministerio profético de Cristo y -en virtud de la 'unción del Santo' (Espíritu) (LG 12)- no puede equivocarse en la fe. En la perspectiva de Lumen Gentium adquieren el apostolado de los seglares (cf. AA, 3) y la tarea misionera (cf. AG 4) una fundamentación expresamente pneumatológica. También la Constitución sobre la revelación, el Decreto sobre el ecumenismo y el Decreto sobre el ministerio y vida de los presbíteros muestran acentuación parecida. Por desgracia, en la Constitución pastoral sobre la "Iglesia en el mundo actual' no son recogidas todas las sugerencias que serían del caso. A pesar de la falta de sistemática (que tampoco cabía esperar), no parece estar justificada la acusación que se hace contra el último concilio, de deficiencia pneumatológica. No es la circunstancia de que el Espíritu Santo se le mencione 258 veces en los textos conciliares, sino el hecho de que las expresiones se formulan en puntos teológicos neurálgicos y decisivos, y no menos el proceso seguido por el concilio mismo, lo que atestigua el redescubrimiento del Espíritu Santo".

(178) Cf. p. e. J. Galot, Cristo, revelador, fundador de la Iglesia, principio de la vida eclesial, en R. Latourelle (ed.), Vaticano II: balance y perspectiva. Veinticinco años después (1962-1987) (Verdad e Imagen, 109), p. 273, Salamanca 1989, pp. 261-273.

(179) Cf. PO 13; GS 78. Véase AG 5. En la alusión a la Trinidad económica de UR 24, que va seguida de la cita de Rm 5, 5 con la que termina el documento, el amor está atribuido al Padre y la virtus al Espíritu.

(180) "La obra de la Redención del género humano es la efusión de la misericordia, o mejor, la autoefusión misericordiosa del Padre por el Hijo en el Espíritu: así podría resumirse la teología 
Testamento (181). Aunque la Iglesia sea tema central en el Concilio, ella es la Iglesia de la Trinidad. La Trinidad tiende, pues, a aparecer vitalmente en todo (182). Aunque leamos el Vaticano II desde la teología postconciliar, no hay que confundir la teología del Concilio con la postconciliar (183). En nuestro recorrido hemos partido de algunos de los vocablos que pudieran connotar la Trinidad en sí, lo que nos llevó a ponernos el problema del Dios uno y de la unidad en la Trinidad. Después de evocar la actividad del Padre, pasamos a algunos aspectos del Hijo y del Espíritu Santo. La actividad de los tres ha desplegado la Trinidad económica ante nuestros ojos y nos ha confirmado en ella.

\section{RESUMEN}

El autor destaca primeramente el escaso uso de algunos términos más específicos de la teología trinitaria, p. e. persona. Así también el vocablo 'relación' nunca es aplicado a la Trinidad. Porque las abundantes referencias a la Trinidad, cuya unidad se muestra en la prácti$\mathrm{ca}$, se desenvuelven casi exclusivamente en el horizonte económico. Todo viene del Padre y todo vuelve a él por Cristo (pasando por su pascua) en el Espíritu. Así la Iglesia, tema central, es designio del Padre, fundada por Cristo cabeza del cuerpo, animada por el Espíritu. Igualmente la revelación es la autocomunicación de Dios, que tiene en Cristo su plenitud y nos llega por el Espíritu. La liturgia, que culmina en la Eucaristía, es el culto público de Cristo cabeza, con su cuerpo, al Padre. La Iglesia misionera se origina de las misiones del Hijo y del Espíritu. Cristo es la plenitud del hombre: no sacrifica lo humano sino que lo dignifica en grado sumo. El plan del Padre es instaurar todo en Cristo, que seamos hijos en el Hijo. El Concilio ha devuelto la Trinidad a la vida y se hace impensable una teología que margine la Trinidad. Pero no hay que confundir la teología del Concilio con la del postconcilio.

trinitaria del Vaticano II" (B. de Margerie, op. cit., 303). M. D. Chenu (Nueva conciencia del fundamento trinitario de la Iglesia, p. 341, Concilium 17, 2 (1981) 340-353) declara: "Aunque haya resultado menos notoria que otras, una de las tramas que sustentaron la prolongada reflexión desarrollada en el Vaticano II consistió en la penetración progresiva de la teología oriental, y precisamente en aquellos puntos en que presenta una inteligencia de la fe distinta de la teología latina... Por lo que ahora nos afecta, el personalismo trinitario redujo sutil y eficazmente el deísmo al que había cedido más o menos el pensamiento occidental, hasta en los conceptos empleados en el Vaticano I".

(181) Según Philippon (op. cit. 343), "El Vaticano II examinará, pues, la acción de cada una de las Tres Personas divinas en el misterio eclesial sin cuidado de precisar si se trata de propiedades personales incomunicables o de apropiación. Utiliza simplemente el lenguaje de la Escritura, dejando a los teólogos el cuidado de interpretar este magisterio con un rigor más científico". Cf. C. Molari, Trinità, col. 1936, en S. Garofalo (ed.), Dizionario del Concilio Ecumenico Vaticano Secondo, Roma 1969, col. 1935-1937.

(182) N. Silanes concluye así un primer artículo (Panorámica trinitaria del Concilio, p. 43s, Est Trin I (1967)7-44): "El Concilio ha obligado a la Iglesia a definirse a sí misma. La Iglesia ha reflexionado sobre su origen y su fin, sobre su ser y sobre su misión. Y como no podía menos de suceder, la Santísima Trinidad ha aparecido como única razón de toda su existencia y de toda su misión... Es la Iglesia una Familia de hijos de Dios, que incorporados a Cristo y conducidos por el Espíritu Santo, caminan hacia el hogar del Padre, donde Dios será todo en todos por toda la eternidad". Cf. J. M. Alonso, Ecclesia de Trinitate, en C. Morcillo González, Comentarios a la Constitución sobre la Iglesia, Madrid 1966, pp. 138-165.

(183) En poder distinguir influye la distancia histórica. 


\begin{abstract}
The author brings the attention to the scant use of some terms specific of the Trinitarian theology, such as person or relation. This last is never applied to the Trinity. Despite the numerous references to the Trinity, whose unity is shown in the practice, these are almost exclusively presented from the economic perspective. Everything comes from the Father, and everything returns to Him by way of Christ (through his Passover) in the Spirit. Thus the Church is the Father's desing, founded by Christ the head of the body, and vivified by the Spirit. Likewise, the Revelation is God's self-communication, which reaches its peak in Christ and comes to us through the Spirit. The liturgy, which comes to its culmination in the Eucharist, is the public cult of Christ Head with his body, to the Father. The origin of the missionary church is funded in the missions of the Son and the Spirit. Christ is the plenitude of Man: This does not sacrifice the Human, but dignifies it to its highest degree. The plan of the Father is to restore everything in Christ, to make us children in the Son. The council has restored the vital role of the Trinity, so that today a theology which discards the Trinity would be inconceivable. Yet, the Council's theology is different from the post-council one.
\end{abstract}

